\title{
Matéria orgânica particulada e atividade bacteriana nos sedimentos superficiais da Baía de Guanabara, no Rio de Janeiro, Brasil
}

\author{
Frederico Sobrinho da Silva ${ }^{*}$, João Graciano Mendonça Filho ${ }^{1}$, Antonio Donizeti de Oliveira ${ }^{1}$, \\ Joalice de Oliveira Mendonça ${ }^{1}$, Sinda Beatriz Viana Carvalhal Gomes ${ }^{1}$, Elisamara Sabadini \\ Santos $^{2}$, Bruno Rodrigues Innecco ${ }^{1}$, Mirian Araújo Carlos Crapez ${ }^{3}$
}

Resumo O objetivo deste trabalho foi analisar as enzimas esterases bacterianas associadas ao aporte orgânico particulado que chega aos sedimentos superficiais da Baía de Guanabara, no Rio de Janeiro. Foram coletadas 30 amostras de sedimento superficial, nas quais foram analisados granulometria, carbono orgânico total, enxofre, atividade das enzimas esterases e componentes da matéria orgânica. Os resultados mostraram que a classe textural ficou entre 62,65 a 85,63\% para silte, 7,51 a 12,87\% para argilas e 4,46 a 29,59\% para areias. O carbono orgânico total e o enxofre médios foram 3,78 e $0,77 \%$, respectivamente. O maior valor de esterase foi na estação $18(4,69 \mu \mathrm{g}$ fluoresceína/h/g) e o menor na 24 $(1,25 \mu \mathrm{g}$ fluoresceína/h/g). A média das atividades foi de 3,20 $\mu \mathrm{g}$ fluoresceína/h/g. A análise de palinofácies revelou a predominância de matéria orgânica amorfa $(82,4 \%)$, palinomorfo $(9,2 \%)$ e fitoclasto $(8,4 \%)$. A matéria orgânica amorfa é predominante em todas as amostras e as atividades das enzimas esterases estão associadas, bem como silte-argila. Os palinomorfos estão ligados às areias. As cutículas, os esporomorfos e os Botryococcus estão diretamente relacionados ao aporte de água fluvial na baía. Os resultados combinados das análises de geoquímica orgânica (análise elementar) e técnicas microscópicas (luz transmitida e fluorescência) apontam fácies orgânica, com o predomínio de matéria orgânica amorfa. A intensa coloração de fluorescência, juntamente com o elevado valor de carbono orgânico total ( $>6 \%)$ indicam alta taxa de preservação e baixo teor de oxigênio livre no ambiente. Esses resultados correspondem a uma fácies orgânica, como aquela encontrada nos folhelhos marinhos, característica de fácies depositada sob uma coluna d'água anóxica persistente, com atividade microbiana anaeróbia.

Palavras-chave: enzimas esterases; palinofácies; sedimento.

\begin{abstract}
Particulate organic matter and bacterial activity in the superficial sediments of Baia de Guanabara, Rio de Janeiro, Brazil. The aim of this work was to analyze bacterial esterases enzymes associated with the organic particulate, which gets to the superficial sediments of the Guanabara Bay, in Rio de Janeiro, Brazil. Thirty samples of superficial sediment were collected, in which grain size, total organic carbon, sulfur, activity of the esterases enzymes, and particulate components of organic matter under microscopy were analyzed. The results had shown that the textural class was between 62.65 to $85.63 \%$ for silt, 7.51 to $12.87 \%$ for clays, and 4.46 to $29.59 \%$ for sand. The average total organic carbon (TOC) and sulphur (S) were 3.78 and $0.77 \%$, respectively. The highest esterases value was found in station $18(4.69 \mu \mathrm{g}$ fluorescein $/ \mathrm{h} / \mathrm{g})$ and the lowest in $24(1.25 \mu \mathrm{g}$ fluorescein $/ \mathrm{h} / \mathrm{g})$. The average of activities was of $3.20 \mu \mathrm{g}$ fluorescein $/ \mathrm{h} / \mathrm{g}$. The palynofacies analysis showed a predominance of the amorphous (82.4\%), palynomorphe (9.2\%), and phytoclast $(8.4 \%)$ organic matters. The amorphous organic matter is predominant in all samples and the esterases enzymes activities are associated with the silt-clay. The palynomorphes are associated with sand. Cuticles, sporomorphes, and Botryococcus are directly related to to fluvial fluxes of rivers. The combined results of the analyses on organic geochemistry (elementary analysis) and microscopical techniques (transmitted and fluorescence light) disclose organic facies, with predominance of amorphous organic matter. The intense fluorescence coloring, together with raised value of total organic carbon ( $>6 \%$ ) indicate high rate of preservation and low content of free oxygen in the environment. These results correspond to an organic facies, like marine shale, which is a characteristic of a deposited facies under persistent anoxic water column with anaerobic microbial activity.
\end{abstract}

Keywords: esterases enzymes; palynofacies; sediment.

\footnotetext{
${ }^{1}$ Laboratório de Palinofácies \& Fácies Orgânica - LAFO; Departamento de Geologia, Instituto de Geociências da Universidade Federal do Rio de Janeiro - UFRJ, Rio de Janeiro (RJ), Brasil. E-mail: fsobrinho@gmail.com, graciano@geologia.ufrj.br ${ }^{2}$ Departamento de Geoquímica, Instituto de Química da Universidade Federal Fluminense - UFF, Niterói (RJ), Brasil. E-mail: esabadini@geoq.uff.br

${ }^{3}$ Laboratório de Microbiologia Marinha - MICROMAR; Departamento de Biologia Marinha da Universidade Federal Fluminense UFF, Niterói (RJ), Brasil. E-mail: mirian.crapez@gmail.com

*Autor correspondente
} 
INTRODUÇÃO Estuários em todo mundo são os sistemas mais produtivos, mesmo sendo de material biológico de produção autóctone, que é a maior fonte de material para os sedimentos. Entretanto, sedimentos estuarinos normalmente acumulam partículas marinhas e de origem continental (Mayer et al. 1988, Cifuentes 1991). Em estuários eutrofizados, as entradas de esgoto orgânico influenciam fortemente a qualidade da matéria orgânica que vai ao sedimento.

A formação dos sedimentos em sistemas marinhos possui grande quantidade de matéria orgânica envolvida em variados e complexos processos de sedimentação de origens continental e marinha. Inicialmente, a matéria orgânica consiste em tipos de compostos, tais como: açúcar, aminoácidos e outros constituintes. Durante o processo de sedimentação, apenas uma porção inicial da matéria orgânica se mantém no sedimento (Premuzic et al. 1982).

Os sedimentos representam o registro dos processos que ocorrem na coluna d'água e são depósitos dos inputs de matérias orgânicas autóctone e alóctone (Fabiano \& Danovaro 1994, Fabiano et al. 1995, Danovaro et al. 1999). Os sedimentos marinhos costeiros têm sido identificados como importantes alocadores de nutrientes regenerados e para as bactérias e, ainda, constituem os agentes para a diagênese da matéria orgânica. A característica fundamental das bactérias é a propriedade catalítica de sintetizar enzimas extracelulares, especializadas na quebra da matéria orgânica, e transformá-las em carbono orgânico de baixo peso molecular (Deming \& Baross 1993).

Os sedimentos marinhos são intensamente colonizados por micro-organismos (bactérias e cianobactérias). Organizam-se em biofilmes e em matrizes extracelulares de polissacarídeos, originando-se complexas associações entre eles e com outros organismos. Assim, os micro-organismos criam micro-hábitats com pronunciado gradiente de parâmetros físicos, químicos e biológicos, capacitando-os a utilizar o substrato e a energia eficientemente (Meyer-Reil 1994, Meyer-Reil \& Köster 2000).

Assim, o objetivo deste trabalho foi analisar as enzimas esterases bacterianas associadas ao aporte orgânico particulado que chega aos sedimentos superficiais da Baía de Guanabara, no Rio de Janeiro.

\section{MATERIAL E MÉTODOS}

Área de estudo A Baía de Guanabara, uma das mais proeminentes do Litoral brasileiro, está localizada no
Estado do Rio de Janeiro entre as latitudes de $22^{\circ} 40^{\prime}$ e $23^{\circ} 00^{\prime}$ Sul e longitude $43^{\circ} 00^{\prime}$ e $43^{\circ} 20^{\prime}$ Oeste (Fig. 1), margeando as regiões metropolitanas das cidades do Rio de Janeiro, Niterói, São Gonçalo, Magé, entre outras. Sua localização ocorre numa região de clima tropical úmido com estação chuvosa, no verão, e seca, no inverno; as chuvas podem exceder $10 \mathrm{~mm}$ em poucas horas, produzindo-se um intenso processo de runnof (Kjerfve et al. 1997).

A bacia de drenagem da Baía de Guanabara tem área aproximada de $4.600 \mathrm{~km}^{2}$ incluindo a mesma, que possui um volume total de água aproximado de $1,87 \times 10^{9} \mathrm{~m}^{3}$ com profundidade média de $5,7 \mathrm{~m}$ (Kjerfve et al. 1997), englobando praticamente quase toda a região metropolitana das cidades do Rio de Janeiro, Niterói e São Gonçalo, entre outras (Amador 1997). A superficie da baía tem aproximadamente $380 \mathrm{~km}^{2}$ (até o alinhamento entre o Forte São João e a Fortaleza Santa Cruz) e perímetro de $131 \mathrm{~km}$, com extensão máxima de $28 \mathrm{~km}$ do Leste ao Oeste e aproximadamente $30 \mathrm{~km}$ do Norte ao Sul (Kjerfve et al. 1997), sofrendo um estreitamento em sua barra (entre a Fortaleza de Santa Cruz e o Forte de São João) e chegando à largura de 1,6 km (Quaresma et al. 2000). Os principais rios que drenam a bacia são: Macacú, Guapiaçu, Guapimirim, Caceribu, Guaxindiba, Guaraí,Imboacica, Magé, Estrela-Inhomirim, Saracuruna, Meriti, Iguaçu e Pavuna.

Segundo o levantamento realizado pela Japan International Cooperation Agency - JICA (1994), a área drenada pela baía tem população aproximada de $11 \mathrm{mi}-$ lhões de habitantes, abrigando o segundo maior parque industrial do Brasil. Esta região possui oito terminais de petróleo, sendo 1 de gás, 12 estaleiros, 2 refinarias de petróleo, 827 postos de serviços, 2 portos comerciais e cerca de 12.500 indústrias. A produção de esgoto doméstico é de $17 \mathrm{~m} / \mathrm{s}$, ocorrendo vazadouros de lixo às margens da baía. Os dejetos industriais líquidos respondem por $25 \%$ das 465 toneladas/dia de matéria orgânica despejadas na baía, sendo que, destas, apenas 68 toneladas/dia recebem tratamento adequado.

As marés são semidiurnas, com variação de $0,7 \mathrm{~m}$, e os picos das correntes de primavera são de $0,5 \mathrm{~m} / \mathrm{s}$ dentro da baía e $1,6 \mathrm{~m} / \mathrm{s}$ próximos a sua entrada. O canal central tem profundidade de 30 a $40 \mathrm{~m}$ e é delimitado por uma isolinha de $10 \mathrm{~m}$ de largura. A topografia do fundo é influenciada pelas correntes de maré que drenam o canal central e pelo alto assoreamento. $\mathrm{O}$ aumento da profundidade depois da entrada do canal central resulta na queda da velocidade das correntes de maré, acarretando no depósito de areias finas e lamas. 
Areias grossas são predominantes no canal central e nas regiões próximas à boca da baía. Extensos depósitos de lamas resultam do ativo transporte de material clástico e da intensa produtividade primária mensurada na área Norte da baía (JICA 1994, Kjerfve et al. 1997).

Uma forte estratificação da coluna d'água com relação ao oxigênio dissolvido é observada em áreas com profundidades maiores de $10 \mathrm{~m}$. Os valores de oxigênio superficial são de 300\% (supersaturados) em zona fótica ( $\cong 5 \mathrm{~m}$ ); contudo, em locais entre 4 a $5 \mathrm{~m}$, as concentrações são menores de $1 \mathrm{~mL} / \mathrm{L}$ (Rebello et al. 1990).

A baía vem sendo gradualmente modificada pelo desmatamento e assoreamento. Essas atividades têm aumentado a velocidade dos fluxos dos rios e o trans- porte do sedimento, resultando-se numa sedimentação de 1 a $2 \mathrm{~cm}$ por ano (Godoy et al. 1998).

A Baía de Guanabara é considerada um dos ambientes mais poluídos da costa brasileira (Rebello et al. 1986, Vandenberg \& Rebello 1986, Leal \& Wagener 1993, Baptista-Neto et al. 2006).

Métodos analíticos Em agosto, novembro e dezembro de 2005, 30 amostras de sedimento superficial (2 $\mathrm{cm}$ ) foram coletadas na Baía de Guanabara em três transectos (primeiro, amostras 01 a 09; segundo, 10 a 20; e terceiro, 21 a 30), usando draga do tipo van-Veen para amostras arenosas e draga tipo Eckman para lamosas (Fig. 1). As amostras foram armazenadas por duas horas em sacos de polipropileno e acondicionadas em gelo até serem levadas ao laboratório, onde prosseguiram às

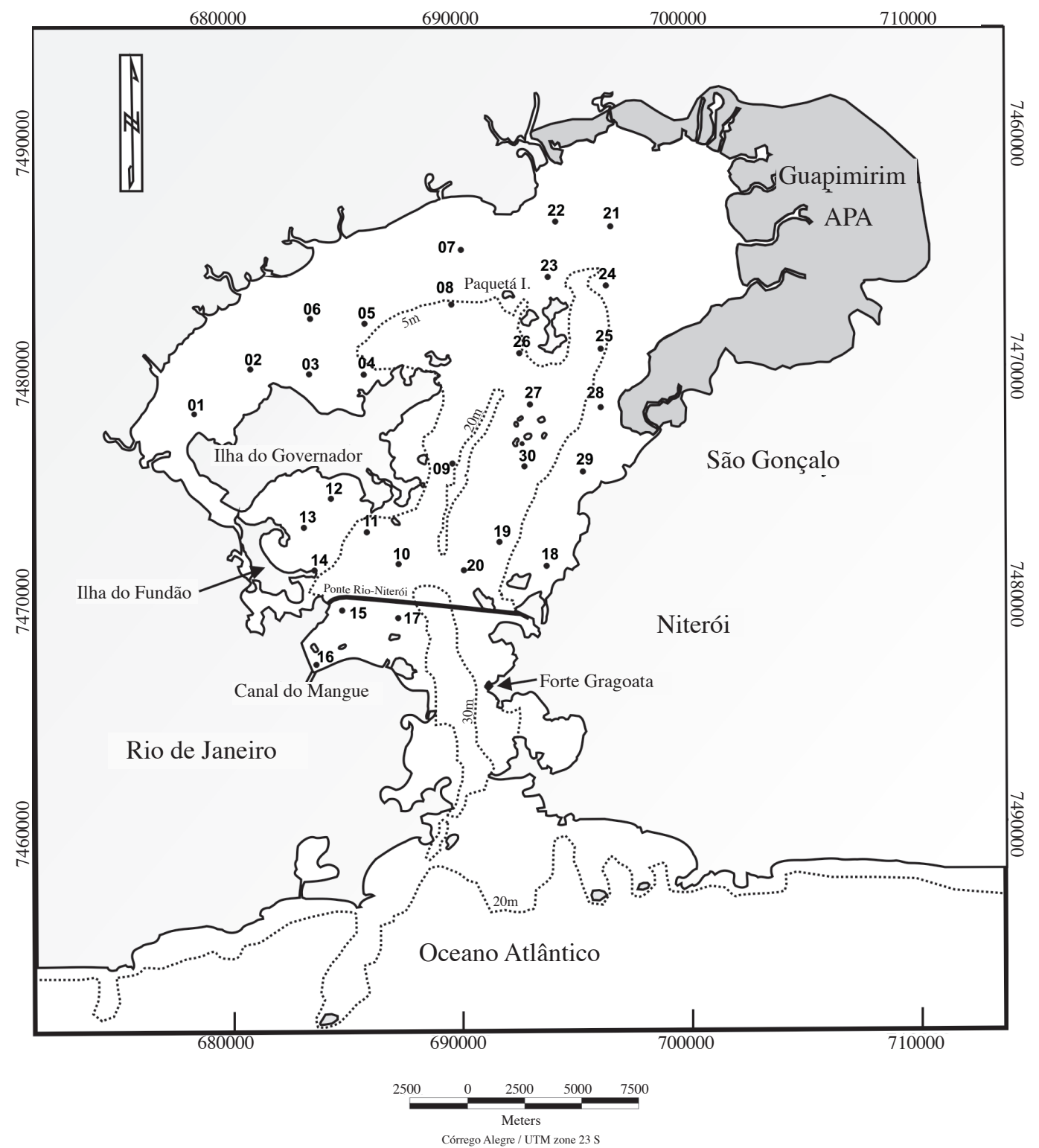

Figura 1 - Mapa da área de estudo com a localização das amostras de sedimento superficial na Baía de Guanabara, no Rio de Janeiro. 
seguintes análises. Todas foram feitas em triplicata, utilizando-se os $2 \mathrm{~cm}$ de sedimento superficial.

A análise granulométrica foi realizada utilizando-se o analisador de partícula à laser CILAS1064L (Ziervogel \& Bohling 2003), após a destruição da matéria orgânica do sedimento e a secagem do material.

O conteúdo de matéria orgânica total (MOT) foi determinado em triplicata, medindo-se a variação do peso seco $\left(60^{\circ} \mathrm{C}, 24\right.$ horas) após calcinação a $450{ }^{\circ} \mathrm{C}$ por duas horas, depois de homogeneizado (Byers et al. 1978).

As determinações do carbono orgânico total (COT) e do enxofre (S) foram realizadas nas amostras de sedimento com tratamento extrativo com diclorometano e ultrassom, no aparelho SC 144 da LECO (Mendonça-Filho et al. 2003).

A atividade das enzimas esterases foi analisada segundo Stubberfield \& Shaw (1990). Esta análise é baseada em compostos fluorogênicos, que são enzimaticamente transformados em produtos fluorescentes, os quais podem ser quantificados usando colorimétrico por espectrofotômetro $(490 \mathrm{~nm})$. Essas enzimas atuam sobre os biopolímeros (carboidratos, proteínas e lipídeos), que são transformados em produtos de baixo peso molecular (oligômeros), fração de carbono orgânico utilizado pela via bacteriana. $\mathrm{O}$ resultado é expresso em $\mu \mathrm{g}$ fluoresceína/h/g (de peso seco de sedimento).

Realizou-se também análise de palinofácies, segundo o padrão de técnicas palinológicas. Essa análise compreendeu o exame qualitativo e quantitativo do querogênio, ou seja, a integração dos aspectos dos componentes da matéria orgânica, tais como: identificação dos componentes particulados individuais, determinação de suas proporções relativas e seu estado de preservação. As partículas orgânicas são divididas em três grupos principais: matéria orgânica amorfa (MOA), fitoclasto e palinomorfo. Para esta análise, utilizou-se técnicas de microscopia de luzes branca transmitida e azul/ultravioleta incidente (fluorescência). Foram contados e identificados 300 componentes da matéria orgânica particulada, obedecendo-se à classificação geral dos principais componentes da matéria orgânica (baseado em Tyson 1995, Mendonça Filho 1999, Mendonça Filho et al. 2002, Mendonça Filho et al. 2009). Após a contagem dos componentes orgânicos particulados, os valores absolutos foram recalculados para percentuais e normalizados a $100 \%$. Além disso, foram confeccionados diagramas binários e ternários para melhor visualização dos resultados.
O resultado da MOA, do fitoclasto e do palinomorfo foi distribuído em um diagrama ternário para entendimento da distribuição da característica sedimentar (Tyson 1993).

As análises estatísticas realizadas foram de correlação com o método de Sperman e a análise de agrupamento, utilizando-se o método de Ward com distância de Manhattan no programa STATISTICA ${ }^{\odot}$ 7.0.

RESULTADOS A análise granulométrica dos sedimentos superficiais da baía ficou entre 62,65 a $85,63 \%$ de silte, 7,51 a $12,87 \%$ de argila e 4,46 a $29,59 \%$ de areia. A litologia para as amostras de sedimento da baía foi caracterizada como lamas. As maiores concentrações de silte foram encontrada a Noroeste da baía, as argilas principalmente na região próxima às ilhas e a São Gonçalo. As areias foram encontradas nas amostras próximas à área de proteção ambiental (APA) de Guapimirim e no canal central (Fig. 2).

O nível de MOT no sedimento apresentou a maior concentração na estação $28(8,35 \%)$, e a menor na $30(0,59 \%)$, com média de $5,62 \%$ para as 30 estações. As maiores concentrações foram encontradas ao lado da APA de Guapimirim (Fig. 2).

O COT variou entre 0,3 a $6,2 \%$ e o $\mathrm{S}$ entre 0,1 a $1,4 \%$. Os valores médios do COT e do $\mathrm{S}$ foram de 3,78 $\pm 1,34 \%$ e $0,77 \pm 0,32 \%$, respectivamente. Os maiores valores de COT foram encontrados ao Norte e Nordeste da baía, enquanto o S se encontrou na saída do rio do município de São Gonçalo e a Noroeste da baía, atrás da Ilha do Governador (Estação 1), como pode ser observado na Fig. 2.

As 30 amostras de sedimento superficial apresentaram atividade das enzimas esterases. O maior valor encontrado foi obtido na estação 18 (4,69 $\mu \mathrm{g}$ fluoresceína/h/g) e o menor na estação 24 $(1,25 \mu \mathrm{g}$ fluoresceína/h/g). A média das atividades foi de $3,20 \mu \mathrm{g}$ fluoresceína/h/g. As estações 1,2 , 6, 12, 16 e 18 mostraram níveis acima de 4,0 $\mu \mathrm{g}$ fluoresceína $/ \mathrm{h} / \mathrm{g}$. Maiores atividades foram encontradas junto às saídas dos rios, a Noroeste da baía, e próximas à saída dos rios de São Gonçalo e da APA de Guapimirim (Fig. 3).

A relação representativa da distribuição média da análise de palinofácies nos sedimentos superficiais revelou a predominância de MOA $(82,4 \%)$, seguida pelo grupo de palinomorfo $(9,2 \%)$ e fitoclasto $(8,4 \%)$. No Grupo MOA, a maior percentagem de distribuição foi da MOA heterogênea fluorescente em todas as estações (80\%). Apenas na estação 18, encontrou-se 5\% de 


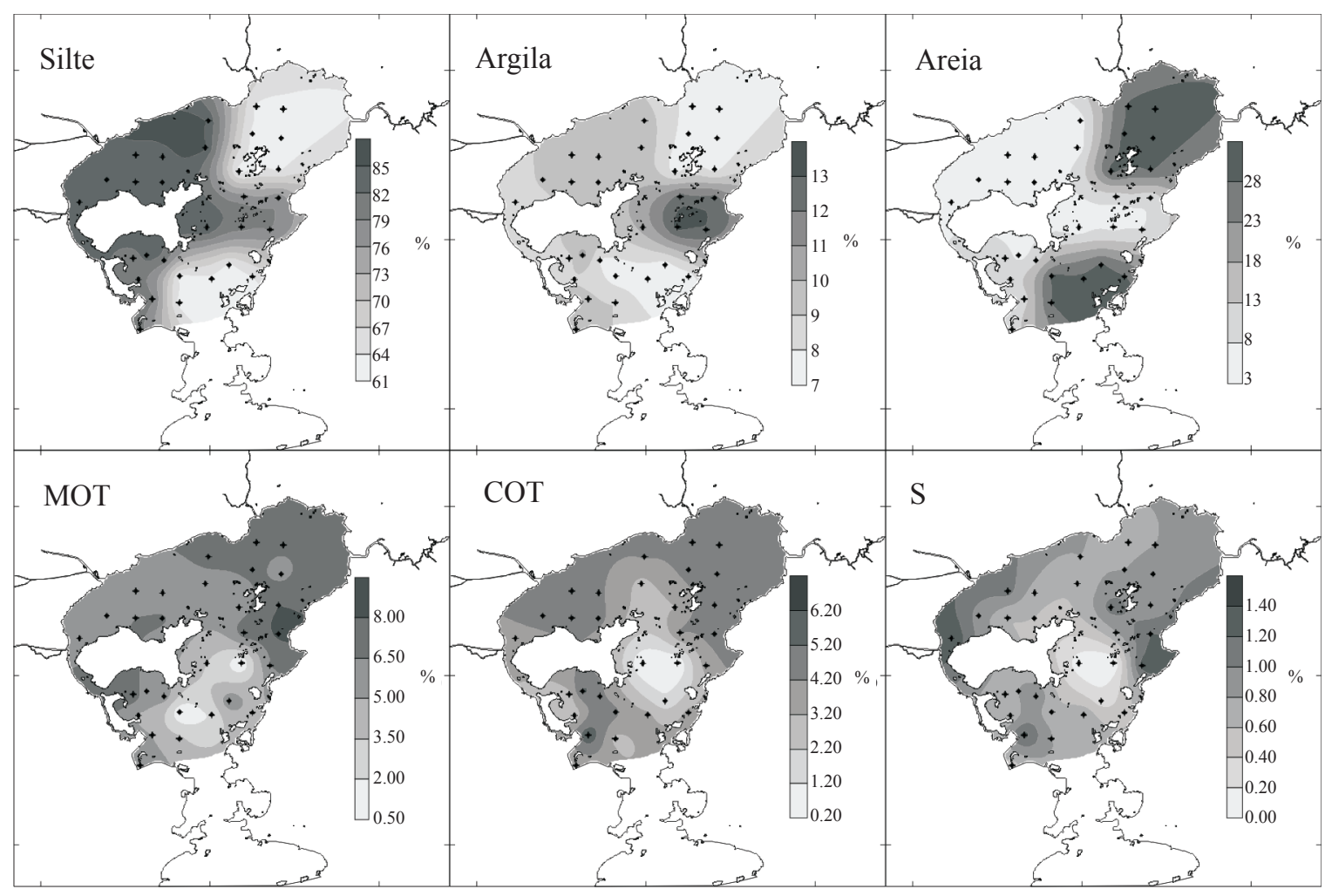

Figura 2 - Distribuição granulométrica, matéria orgânica total (MOT), carbono orgânico total (COT) e enxofre (S) nos sedimentos superficiais da Baía de Guanabara - RJ.

MOA homogênea não fluorescente. Já na 17, houve 9\% de MOA heterogênea não fluorescente (Figs. 3 e 4).

O Grupo Palinomorfo está representado pela distribuição média entre os grupos de esporomorfos ( $8 \%$ ), seguido de dinocistos $(2,4 \%)$. Os esporomorfos ocorreram em todas as amostras superficiais dos sedimentos com variação entre 0,3 a $75 \%$. Já os dinocistos estão distribuídos em três manchas nos sedimentos superficiais (amostras de 1 a 6; 9 a 15 e 24 a 19) e variando entre 0,3 a $17 \%$. Apesar dos grupos bem característicos, foi possível encontrar Botryococcus na amostra 22, com $0,3 \%$ (Fig. 3).

As correlações positivas significativas $(\mathrm{p}<0,05)$ foram entre silte e argila $(\mathrm{R}=0,57)$, COT e MOT $(\mathrm{R}=0,38), \mathrm{S}$ e COT $(\mathrm{R}=0,51)$, fitoclastos entre si e com esporomorfos $(R=0,76 ; 0,59 ; 0,58 ; 0,46 ; 0,62$ e 0,44$)$. Enquanto que as correlações negativas, porém significativas $(p<0,05)$, foram entre areia e silte $(R=-0,90)$, $S$ com cutícula e esporomorfos $(\mathrm{R}=-0,46 ;-0,47)$, MOA com os fitoclastos-cutícula-esporomorfos e dinoflagelados $(\mathrm{R}=-0,61 ;-0,64 ;-0,44 ;-0,82$ e $-0,39)$, como visto na Fig. 5.

O agrupamento da distribuição das amostras (Fig. 6), quando cortado em $30 \%$, gerou quatro áreas dentro da baía. O primeiro Grupo A (estações 17 e 18) acondicionou as amostras ligadas à MOA homogênea não fluorescente e as grandes quantidades de esporos, indicativos de material de origem continental. O Grupo B (estações 10, 19, 20 a 26) foi direcionado pelas atividades das esterases bacterianas de baixa intensidade da quebra de matéria orgânica e área de maior hidrodinâmica influenciada pelo canal central. O Grupo C (estações 27 a 30) representa as altas porcentagens de MOA heterogênea fluorescente (97 a 100\%). O Grupo D foi dividido em dois subgrupos, o Grupo E (estações 3 e 4) foi direcionado pelas análises de MOA heterogênea fluorescente com conteúdo na faixa de $66 \%$. O Grupo F (estações 1, 2, 5, 6, 7, 8, 11 a 16), que é a área onde a baía é mais homogênea em relação aos resultados das análises, em função da baixa hidrodinâmica, é considerado pela literatura o mais impactado.

DISCUSSÃO A Baía de Guanabara se estreita no alinhamento do Forte Gragoatá com o Aeroporto Santos Dumont, o que resulta na redução das velocidades das correntes e aumenta o depósito de finos no sedimento nas laterais do canal. Os sedimentos são primariamente argila-siltosa e silte-argiloso depositado em função das ondas de SSW e das correntes de maré. As partes Norte e Central da baía são caracterizadas pela presença de sedimentos lamosos. Essas áreas são protegidas das ações das ondas e das correntes de maré e são de baixa energia 


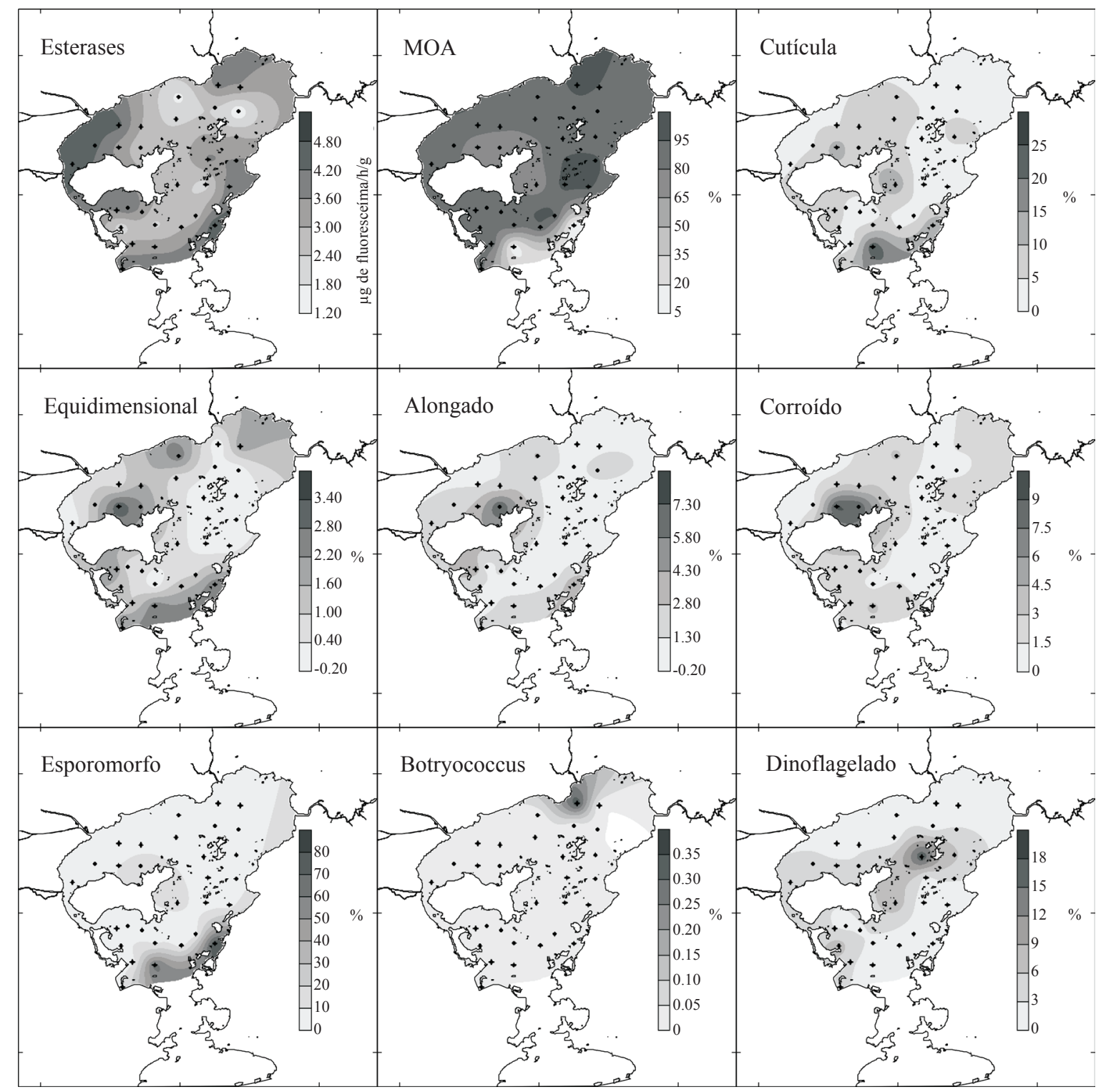

Figura 3 - Distribuição espacial das enzimas esterases e componentes da matéria orgânica na Baía de Guanabara-RJ.

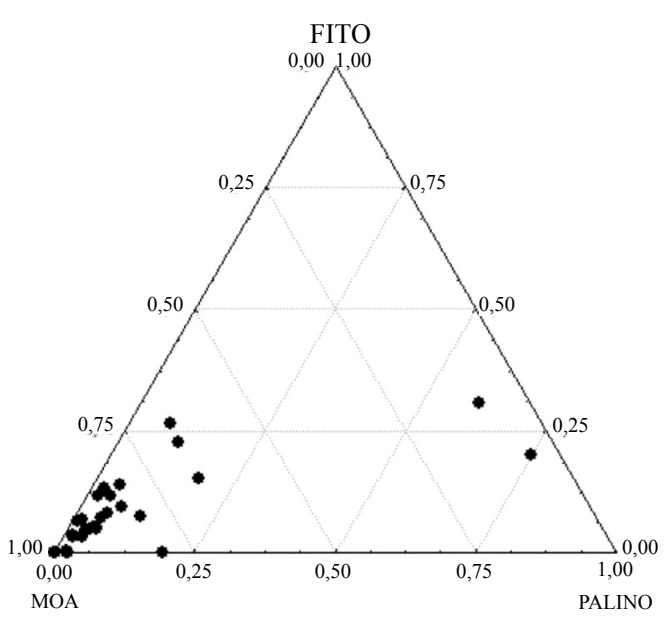

Figura 4-Diagrama ternário dos três grupos principais da matéria orgânica (MOA: matéria orgânica amorfa; PALINO: palinomorfo; FITO: fitoclasto) nos sedimentos superficiais da Baía de Guanabara - RJ.

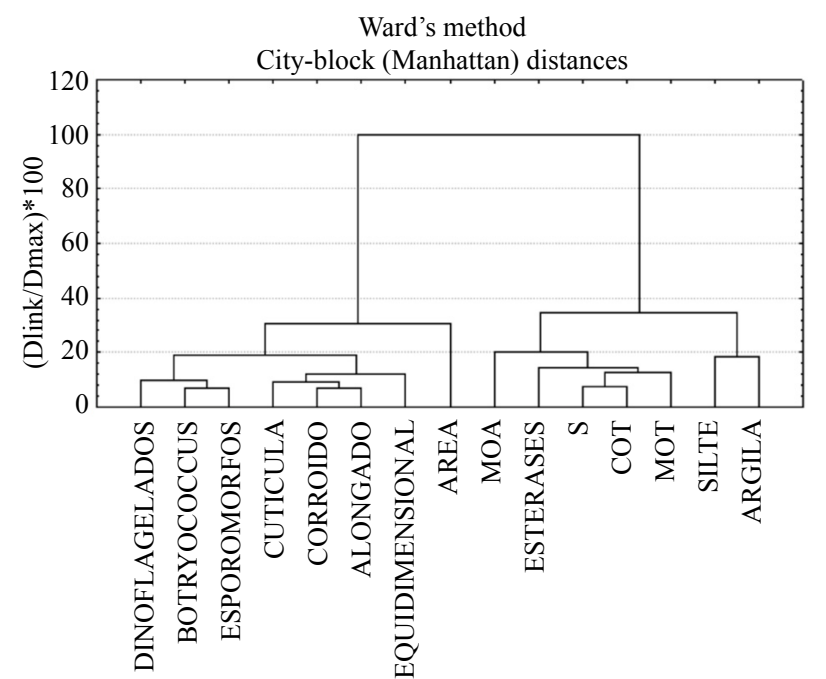

Figura 5-Agrupamento das análises realizadas utilizado o Método de Ward e distância de Manhattan (MOA: matéria orgânica amorfa; S: enxofre; COT: carbono orgânico total; MOT: matéria orgânica total). 
Ward's method

City-block (Manhattan) distances

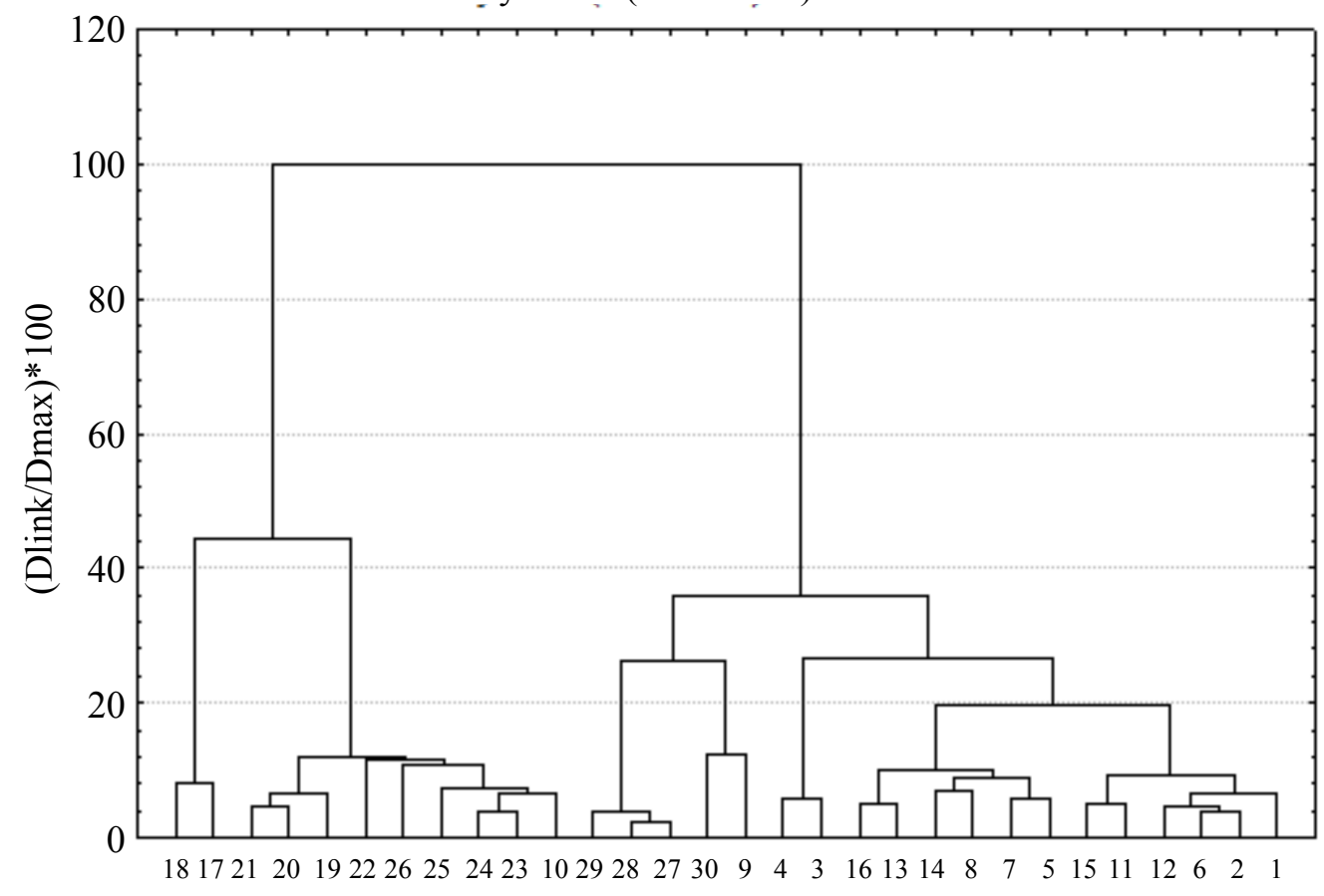

Figura 6-Agrupamento das estações amostradas na Baía de Guanabara - RJ, utilizando o Método de Ward e distância de Manhattan.

hidrodinâmica, acumulando sedimento composto por silte e argila (Kjerfve et al. 1997, Quaresma et al. 2000, Catanzaro et al. 2004, Baptista-Neto et al. 2006).

Segundo Hedges et al. (1997) e Premuzic et al. (1982), compostos orgânicos agregados aos argilominerais na coluna d'água têm sido depositados nos sedimentos em baixa tensão de oxigênio, formando um sedimento rico em matéria orgânica e em condições subóxicas e anóxicas.

Os níveis médios de MOT nos sedimentos superficiais variaram entre 4 a $6 \%$. Nas 30 amostras de sedimento, os maiores níveis de MOT $(8,4 \%)$ foram encontrados nas áreas próximas à APA de Guapimirim, que protege uma das mais importantes de manguezais da baía. Essa área de mangue contribui com mais MOT que a área Noroeste da baía, com poucos manguezais e atividade industrial petroleira. Esses valores foram semelhantes ao encontrados por Mendonça-Filho et al. (2003), Catanzaro et al. (2004) e Baptista-Neto et al. (2006). Entretanto, Barbosa et al. (2004), amostrando no canal da Ilha do Fundão próximo a Noroeste da baía, encontraram concentrações muito elevadas $(\sim 15$ a $27 \%$ ) e alta concentração de sedimento fino com alta plasticidade.

Dell'anno et al. (2002), na Itália, relataram concentrações de MOT variando entre 1,8 e 5,4\%, em março e setembro de 2000, sendo os pontos de amostragem distribuídos em 17 cidades litorâneas. Outros níveis de MOT em 43 amostras de sedimentos superficiais na Baía de Ubatuba, em São Paulo, foram encontrados por Burone et al. (2003), com variações entre 0,97\%, para um dos pontos com maior contato com o mar aberto, e $17,27 \%$, na foz de um rio localizado no interior da mesma baía. No estuário de Santos, em São Paulo, Siqueira et al. (2006) verificaram a variação dos conteúdos de MOT e os resultados descritos oscilaram entre 0,16 e $9,94 \%$, demonstrando-se maior variação em relação à Baía de Guanabara. Porém, apresentaram uma média inferior com $3,87 \pm 2,63 \%$. Os dados mostraram maiores teores de MOT em ambientes de baixa energia e valores relativamente menores nos setores onde os processos hidrodinâmicos são mais intensos, de acordo com as características dos resultados obtidos para a baía. A variação do conteúdo de MOT encontrada por Laut et al. (2007) no estuário do rio Itacorubí, em Santa Catarina, variou entre 3,58 a 4,54 \%, e é classificada como típica de sistemas estuarinos.

Os valores de COT foram entre 0,3 a $6,2 \%$, similares aos de sedimento superficial, encontrados na literatura. Eichler et al. (2003) analisaram 26 amostras de sedimento superficial na Baía de Guanabara e encontraram valores de COT entre 0,018 a $5,763 \%$, os maiores foram em áreas de menor circulação. Vilela et al. (2003) encontraram valores de COT variando entre 0,05 
a 4,81\% em 42 amostras de sedimentos superficiais da Baía de Guanabara. Mendonça-Filho et al. (2003) encontraram variações entre 0,04 a $6,1 \%$ em 25 amostras de sedimento superficial da Baía de Guanabara e 4,14\% na Enseada de Jurujuba. Os mesmos autores sugerem que o sedimento superficial com COT similar a $4 \%$ são caracterizados como ambiente desóxico-anóxico, com alta taxa de preservação. Em oito amostras feitas por Carreira et al. (2004), em diferentes pontos da baía, levando-se em consideração as secções de até $6,5 \mathrm{~cm}, o$ menor teor de COT $(2,68 \%)$ foi verificado para a região próxima à refinaria REDUC e o teor mais elevado na região Nordeste $(4,75 \%)$, próximo aos manguezais. Fernandez et al. (2005) verificaram nove pontos distribuídos no interior da baía e o ponto que demonstrou menor porcentagem de COT $(0,93 \%)$ encontra-se na região próxima à APA de Guapimirim. No entorno da Ilha do Governador e na praia de Botafogo, ocorreuse uma maior porcentagem (5,52\%). Em um trabalho de Santos et al. (2008), os teores de COT variaram na faixa de 0,12 a $8,55 \%$. Os teores se encontraram mais elevados $(7,64$ e $8,55 \%)$ em estações diretamente afetadas por efluentes de uma pequena fábrica de processamento de pescado na enseada de Jurujuba e no canal Ary Parreiras, em Icaraí, por esgoto.

Já em estudos realizados em outras baías, como a de Ubatuba, em São Paulo, as concentrações de COT encontradas por Burone et al. (2003) variaram entre 0,10 e $3,57 \%$. Por meio dos resultados, pode-se concluir que, em geral, a distribuição do carbono orgânico está diretamente associada com a textura dos sedimentos. No entanto, há indicações de que alguns pontos estão relacionados à entrada da matéria orgânica dos rios e a uma área de deposição no meio da baía, originada pela circulação anti-horária das águas. Ainda no estado de São Paulo, Siqueira et al. (2006) verificaram, para o estuário de Santos, concentrações de carbono orgânico presente nas amostras de sedimentos com variações de 0,09 a 5,78\%, com média de $2,25 \pm 1,53 \%$ para a área estudada. $\mathrm{O}$ teor mais elevado nas áreas sob influências dos canais de Santos e São Vicente, possivelmente, está associado à carga poluidora orgânica que afluiu para esses setores nos últimos anos. Com base nesse resultado, Siqueira et al. (2006) concluíram que os contínuos despejos de origem doméstica e industrial contribuíram para o aumento das concentrações de compostos orgânicos no estuário de Santos.

O S variou entre 0,1 a $1,4 \%$, o elemento apresentou as menores variações de estação para estação, encontrando-se dentro da média da literatura. Ainda, no trabalho de Fernandez et al. (2005), o S foi um elemento que igualmente não sofreu grandes variações em sua porcentagem. Porém, os autores demonstram diferenças entre as regiões da baía em relação às concentrações do elemento S. Para Fernandez et al. (2005), o ponto que encontra-se na região próxima ao manguezal apresentou menor porcentagem $(0,07 \%)$. Na região da parte central da baía e no Porto de Niterói, apresentouse maior porcentagem (1,01 e 1,55\%, respectivamente). Resultados esses, que, comparados ao presente trabalho, encontraram-se contrários, diferente de outros estudos em outros estuários, como na Baía de Ubatuba, em São Paulo, onde, com oscilações ainda menores, Burone et al. (2003) verificaram que o $\mathrm{S}$ atingiu teores variando entre 0,01 e $0,48 \%$. Frente a esses resultados, Siqueira et al. (2006) verificaram para o estuário de Santos que o $\mathrm{S}$ foi o elemento que apresentou grandes variações, oscilando entre 0,03 e 47,93\%, com média de $6,03 \pm 11,10 \%$.

Concluiu-se que os sedimentos superficiais do estuário estariam sofrendo com condições redutoras, devido aos teores de $\mathrm{S}$ total encontrados nas áreas amostradas. Duas possíveis fontes foram apontadas por Siqueira et al. (2006). A primeira pelo provável aumento do $\mathrm{S}$ decorrente da formação e acumulação de sulfeto, de origem da redução de $\mathrm{S}$ liberado pelas indústrias, e do complexo siderúrgico de Cubatão próximo ao estuário. Outra provável rota de introdução de sulfeto pode ser via manguezal, já que é um ecossistema que acumula muito sedimento por se encontrar numa área de deposição, na qual as águas perdem a capacidade de transporte e acumulam partículas finas. Os menores teores de $\mathrm{S}$ total foram encontrados na Baía de Santos, devido à ligação com o mar aberto.

Nos 30 pontos de sedimento superficial ao longo da Baía de Guanabara, determinou-se um valor médio de 3,20 $\mu \mathrm{g}$ de fluoresceína/h/g da atividade das esterases. Contudo, Crapez et al. (2001) determinaram $0,54 \mu \mathrm{g}$ de fluoresceína $/ \mathrm{h} / \mathrm{g}$ de atividade das esterases em sedimentos arenosos da Praia de Boa Viagem. Crapez et al. (2003) encontraram padrões diferentes na determinação enzimática realizada em diferentes estações do ano, com um máximo de $0,17 \mu \mathrm{g}$ de fluoresceína/h/g de atividade da enzima das esterases no inverno. As atividades das esterases foram altas em amostras no Porto de Niterói (Baía de Guanabara / S.E.), 3,63 $\mu \mathrm{g}$ de fluoresceína/h/g (Baptista-Neto et al. 2004). Em termos de metabolismo bacteriano, Silva et al. (2008) encontraram uma teia bêntica microbiana completamente anaeróbia de baixa 
eficiência energética, indicados pelos processos de fermentação, desnitrificação e sulfato-redução, responsáveis pelo ciclos biogeoquímicos e ciclagem da matéria orgânica.

A MOA corresponde ao componente orgânico derivado de atividades bacterianas, fitoplâncton e agregados orgânicos degradados (Tyson 1993). Outros materiais amorfos podem ser produto de material de vegetais superiores (Bustin 1988); porém, este tipo de material não é considerado MOA no seu "sensu" usual (Tyson 1995). A elevada abundância relativa de MOA exibindo intensa coloração de fluorescência é característica das áreas de alta preservação de matéria orgânica, devido às condições redutoras, especialmente em áreas de alta produtividade primária (Tyson 1993, 1995). Áreas afastadas de atividade fluviodeltaica intensa (ambientes de baixa energia) também apresentam elevados percentuais de MOA, uma vez que ocorre processo de diluição por esporomorfos e fitoclastos (Tyson 1987, 1989, 1993, Bustin 1988). Por vezes, em fácies deltaicas proximais de baixa energia pode ser possível que algum material amorfo presente seja o produto da degradação de vegetais superiores (Mendonça Filho \& Menezes 2000). De acordo com Jones (1987), o predomínio de MOA com intensas colorações de fluorescência associado a elevados valores de índice de hidrogênio é indicativo de fácies orgânica depositada sob uma coluna d'água anóxica persistente, que usualmente ocorre em ambientes lacustres, bem como folhelhos marinhos e ambientes carbonáticos.

Os resultados do agrupamento mostraram os palinomorfos ligados ao depósito da fração arenosa. Outros autores relatam que os efeitos diversos podem também levar à ocorrência de concentrações elevadas de palinomorfos em sedimentos ricos em material síltico de granulação fina a média, devido, principalmente, à equivalência hidrodinâmica existente entre esse material sedimentar e os constituintes palinomorfos (Müller 1959, Wall et al. 1977, Tyson 1993).

Os esporomorfos apareceram em toda extensão da baía, predominando em maiores concentrações nas regiões direcionadas a saídas dos rios. Normalmente estão representados pelos esporos de briófitas, pteridófitas e pelos grãos de pólen de gimnospermas e angiospermas. Elevadas abundâncias de esporomorfos são encontradas em áreas deltaicas, porém, em áreas off shore, a quantidade destes decresce rapidamente (Müller 1959, Darrell \& Hart 1970). Groot et al. (1965) enfatizam a importância das mudanças do nível relativo do mar, da extensão da plataforma e das diferenças nas distâncias de transporte pelas fontes fluviodeltaicas na abundância e diversidade de esporomorfos presentes no sedimento. Já a abundância de esporomorfos está mais correlacionada com a proximidade de deltas do que com a distância da costa (Stanley 1965). Uma assembleia de esporomorfos relativamente diversificada ocorre em baías interdistributárias e ambientes do tipo lagunar (Denison \& Fowler 1980, Bustin 1988, Whitaker et al. 1992). Bacias oceânicas ou outras permanentemente com águas estratificadas são frequentemente dominadas por altas percentagens de esporomorfos, com baixa abundância absoluta (Habib 1982).

Nas amostras de sedimento superficial, o grupo dos dinoflagelados ocorre em maior porcentagem na região fronteiriça entre as águas oceânicas do canal central e as dos rios da APA (amostras de 26 a 17\%).

Devido à sensibilidade dos dinoflagelados aos fatores ambientais, sua utilização é ampla em estudos de paleopalinologia e palinofácies, constituindo excelentes organismos bioindicadores, registrados em diversos estudos (Wall et al. 1977, Dale 1996, Jaramillo \& ObohIkuhenobe 1999). A abundância absoluta de dinocistos não está simplesmente relacionada com a produtividade primária, pois parte da sua distribuição é modificada por fatores sedimentológicos e devido ao fato de os dinocistos constituírem uma pequena proporção inconsistente da população dos dinoflagelados e dos componentes fitoplanctônicos totais (Wall et al. 1977). Uma floração de um determinado táxon sugere descontinuidade da salinidade e da temperatura da coluna d'água, que ocorre em sistemas fronteiriços ambientais (Tyson 1995, Jaramillo \& Oboh-Ikuhenobe 1999). Jaramillo \& Oboh-Ikuenobe (1999) afirmam que o grande número de cistos engloba espécies que habitam regiões costeiras e neríticas (porções estuarinas - 20 de salinidade e porções marinhas - 35 de salinidade), e os end-members (cistos viventes em água doce, salobra e oceânica) também são bem distintos.

Aalga do gênero Botryococcus foi encontrada próxima à saída de um rio a Nordeste da baía. Esse gênero apresenta distribuição do Ordoviciano ao Recente e compreende uma colônia com células cônico-cilíndricas, densamente unidas com tamanho variando entre 5 a $60 \mu \mathrm{m}$ (Batten \& Grenfell 1996). Botryococcus e Pediastrum podem ocorrer conjuntamente, porém indicam preferências ecológicas distintas. A salinidade parece ser um fator significativo para a ocorrência desses componentes, pois as algas do gênero Botryococcus suportam grandes variações do teor da salinidade (del Papa et al. 2002), sendo registradas também em fácies temporariamente hipersalinas (Hunt 1987). A porcentagem de algas do gênero 
Botryococcus em sedimentos marinhos pode ser indicativa da proximidade relativa de áreas fonte fluviodeltaicas e/ou redeposição a partir dessas áreas fonte. Botryococcus aumentam sua capacidade de flutuação, sendo transportados de áreas deltaicas para a plataforma, onde são componentes minoritários da assembleia de componentes da matéria orgânica (Tyson 1995).

Do grupo fitoclasto, as cutículas apresentaram maior ocorrência nas amostras de sedimento superficial. A dominância de fitoclastos em assembleias de componentes orgânicos particulados é devido à combinação da natureza proximal da fácies, às condições geralmente óxicas e à resistência relativamente elevada de tecidos lignificados (Tyson 1993). As variações no conteúdo do tipo de fitoclasto estão relacionadas às tendências de preservação seletiva (tendência proximal-distal) e a sedimentação seletiva relacionada às condições hidrodinâmicas (Tyson 1995, Mendonça Filho 1999). Em regiões próximas de fontes fluviais, as abundâncias relativas de fitoclastos não opacos são mais elevadas, nas quais tais partículas diluem qualquer tipo de fitoclasto opaco, palinomorfo ou MOA presentes. Em alguns casos, elevada abundância relativa de fitoclastos pode indicar condições oxidantes, nas quais somente o material mais refratário é preservado (Tyson 1989).

Tyson $(1984,1989)$ descreve que, em ambientes marinhos, a elevada percentagem de fitoclasto está fortemente relacionada à ocorrência e frequência de turbiditos. Alto suprimento de fitoclastos pode diluir os outros componentes orgânicos e refletir características proximais, nas quais a deposição ocorre próximo à flora-mãe. Em estudos de palinofácies de sedimentos pleistocênicos do talude continental da Bacia de Campos, Menezes
(2002) determinou assembleias de componentes da matéria orgânica com predomínio de fitoclastos (principalmente cutículas), tendo características de deposição em fácies proximais (fluviodeltaica) à de talude e de bacia marginal.

CONCLUSÕES O Grupo da MOA é predominante nas amostras e as atividades das enzimas esterases estão associadas a esse material particulado, bem como à fração fina de sedimentos.

Os palinomorfos estão ligados à fração arenosa. As cutículas, os esporomorfos e a ocorrência do gênero Botryococcus estão diretamente ligados ao aporte de água fluvial na baía.

Os resultados combinados das análises de geoquímica orgânica (análise elementar) e técnicas microscópicas (luz transmitida e fluorescência) indicam fácies orgânica, com o predomínio de MOA, que indica uma intensa atividade microbiológica. A intensa coloração de fluorescência, juntamente com o elevado valor de COT $(>6 \%$ ), indica uma alta taxa de preservação e um baixo teor de oxigênio livre no ambiente, respectivamente. Essa é característica de fácies orgânica depositada sob uma coluna d'água anóxica persistente, correspondente aos folhelhos marinhos. A camada anóxica induz o crescimento de microbiota anaeróbia, com metabolismo de baixo rendimento energético, que favorece a ocorrência do fenômeno de preservação da matéria orgânica.

AGRADECIMENTOS Ao Conselho Nacional de Desenvolvimento Cientifico e Tecnológico (CNPq), pelo financiamento da bolsa de Pós-doutorado Júnior (PDJ - processo n ${ }^{\circ}$ 150095/2007-4).

\section{Referências}

Amador E.S. 1997. Baía de Guanabara e ecossistemas periféricos: homem enatureza. Riode Janeiro, REPROART, $539 \mathrm{p}$.

Baptista Neto J.A., Crapez M.A.C., Mcalister J.J., Vilela C.G. 2004. Concentration and bioavailability of heavy metals in sediments from Niterói harbour (Guanabara Bay/S.E. Brazil). Journal of Coastal Research, 20:1-7.

Baptista Neto J.A., Gingele F.X., Leipe T., Brehme I. 2006. Spatial distribution of heavy metals in superficial sediments from Guanabara Bay: Rio de Janeiro, Brazil. Environmental Geology, 49:1051-1063.

Barbosa M.C., Almeida M.D.S., MarizD.F.,Almeida J.L.D.S.S. 2004. Studies of channel sediments contaminated with organics and heavy metals. Journal of Hazard Materials, 110:29-38.

Batten D.J. \& Grenfell H.R. 1996. Botryococcus. In:
Jansonius J., McGregor D.C. (eds.). Palynology: principles and applications. American Association of Stratigraphic Palynologists Foundation, 1:205-214.

Burone L., Muniz P., Pires Vanin A.M., Rodrigues M. 2003. Spatial distribution of organic matter in the surface sediments of Ubatuba Bay (Southeastern - Brazil). Anais da Academia Brasileira de Ciências, 75:77-90.

Bustin R.M. 1988. Sedimentology and characteristics of dispersed organic matter in Tertiary Niger Delta: origin of source rocks in a deltaic environment. American Association of Petroleum Geologists Bulletin, 72:277-298.

Byers S., Mills E., Stewart P. 1978. Comparison of methods of determining organic carbon in marine sediments, with suggestions for a standard methods. Hydrobiologia, 58:43-47.

Carreira R.S., Wagener A.L.R., Readman J.W., Fileman T.W., 
Macko S.A., Veiga A. 2004. Sterols as markers of sewage contamination in a tropical urban estuary (Guanabara Bay, Brazil): space-time variations. Estuarine, Coastal and Shelf Science, 60:587-598.

Catanzaro L.F., Baptista Neto J.A., Guimarães M.S.D., Silva C.G. 2004. Distinctive sedimentary processes in Guanabara Bay - SE/Brazil, based on the analysis of echo-character (7.0 kHz). Revista Brasileira de Geofisica, 22:69-83.

Cifuentes L.A. 1991. Spatial and temporal variations in terrestrially derived organic matter from sediments of the Delaware estuary. Estuaries, 14(4):414-419.

Crapez M.A.C., Baptista Neto J.A., Bispo M.G.S. 2003. Bacterial enzymatic activity and bioavailability of heavy metals in sediments from Boa Viagem Beach (Guanabara Bay). Anuário do Instituto de Geociências da UFRJ, 26:58-64.

Crapez M.A.C., Cavalcante A.C., Bispo M.G.S., Alves P.H. 2001. Distribuição e atividade enzimática de bactérias nos limites inferior e superior entre-marés na Praia de Boa Viagem, Niterói, R.J., Brasil. In: Moraes R. et al. (ed.). Efeito de poluentes em organismos marinhos, São Paulo, Arte e Ciência, Villipress, p. 129-138.

Dale B. 1996. Dinoflagellate cyst ecology: modeling and geological applications. In: Jansonius J. \& McGregor D.C. (eds.). Palynology: Principles and Applications. AASP Foundation, Salt Lake City, 3: p. 1249-1275.

Danovaro R., Dell'Anno A., Pusceddu A., Fabiano M. 1999. Nucleic acid concentrations (DNA, RNA) in the continental and deep sea sediments of the eastern Mediterranean: relationships with seasonally varying organic inputs and bacterial dynamics. Deep-Sea Research I, 46:1077-1094.

Darell J.H. \& Hart G.F. 1970. Environmental determinations using absolute miospore frequency, Mississipi River delta. Geological Society of America Bulletin, 81:2513-18.

Del Papa C., García V., Quattrocchio M. 2002. Sedimentary facies and palynofacies assemblages in an Eocene perennial lake, Lumbrera formation, northwest Argentina. Journal of South American Earth Sciences, 15:553-569.

Dell'Anno A., Mei M.L., Pusceddu A., Danovaro R. 2002. Assessing the trophic state and eutrophication of coastal biochemical composition of sediment organic matter. Marine Pollution Bulletin, 44:611-622.

Deming J.W. \& Baross J.A. 1993. The early diagenesis of organic matter bacterial activity. In: Engel M. H., Macko S. A. (ed.). Organic Geochemistry - Principles and Applications, New York, Plenum Press, p. 119-144.

Denison C. \& Fowler R.M. 1980. Palynological identification of facies in a deltaic environment. In: Proceedings of the Meeting on the Sedimentation of North Sea Reservoir Rocks, Geilo, Norwegian Petroleum Society, Oslo, 12:1-22.

Eichler P.P.B., Eichler B.B., Miranda L.B., Pereira E.R.M., Kfouri P.B.P., Pimenta F.M. et al. 2003. Benthic Foraminiferal Response to Variations in Temperature, Salinity, Dissolved Oxygen and Organic Carbon, in the Guanabara Bay, Rio de janeiro, Brazil. Anuário do Instituto de Geociências da UFRJ, 26:36-51.

Fabiano M. \& Danovaro R. 1994. Composition of organic matter in sediments facing a river estuary (Tyrrhenian Sea): relationships with bacteria and microphytobenthic biomass. Hydrobiologia, 277:71-84.

Fabiano M., Danovaro R., Fraschetti S. 1995. A three-year time series of elemental and biochemical composition of organic matter in subtidal sediments of the Ligurian Sea (northwestern Mediterranean). Continental Shelf Research, 15:1453-1469.

Fernandez M.A., Wagener A.D.R., Lima Verde A.M., Scofield A.L., Pinheiro F.M., Rodrigues E. 2005. Imposex and surface sediment speciation: A combined approach to evaluate organotin contamination in Guanabara Bay, Rio de Janeiro, Brazil. Marine Environmental Research, 59(5):435-452.

Godoy J.M., Moreira I., Bragança M.J., Wanderley C., Mendes L.B. 1988. A study of Guanabara Bay sedimentation rates. Journal of Radioanalytical and Nuclear Chemistry, 227(12):157-160.

Groot J.J., Groot C.R., Ewing M., Burckle L., Conolly J.R. 1965. Spores, pollen, diatoms and provenance of the Agentine basin sediments. Progress in Oceanography, 4:179-217.

Habib D. 1982. Sedimentary supply origin of cretaceous black shales. In: Schlanger S.O. \& Cita M.B. (eds.). Nature and origin of Cretaceous Carbon-rich Facies. Academic Press of London, p. 113-27.

Hedges J.I., Keil R.G., Benner R. 1997. What happens to terrestrial organic matter in the ocean? Organic Geochemistry, 27(5-6):195-212.

Hunt J.W. 1987. Relationship between microlithotype and maceral composition of coals and geological setting of coal measures in Permian Basins of Eastern Australia. Australian Coal Geology, 4(2):484-501.

Jaramillo C.A. \& Oboh-Ikuenobe F.E. 1999. Sequence stratigraphic interpretations from palynofacies, dinocyst and lithological data of Upper Eocene-Lower Oligocene strata in southern Mississippi and Alabama, U.S. GulfCoast. Palaeogeography, Palaeoclimatology, Palaeoecology, 145:259-302.

JICA - Japan International Cooperation Agency. 1994. The study on recuperation of the Guanabara Bay ecosystem, Tokyo, Kokusai Kogyo Co., Ltd., 8 v.

Jones R.W. 1987. Organic Facies. In: Brooks J. \& WelteD. (eds). Academic Press. Advances in Petroleum Geochemistry, 2:1-90.

Kjerfve B., Ribeiro C., Dias G., Filippo A, Quaresma V. 1997. Oceanographic characteristics of an impacted coastal bay: Baía de Guanabara, Rio de Janeiro, Brazil. Continental Shelf Research, 17(13):1609-1643.

Laut L.L.M., Silva F.S., Bonetti C., Figueiredo Jr A.G., Crapez M.A.C. 2007. Foraminíferos e atividade bacteriana aplicados no diagnóstico ambiental do estuário do rio Itacorubí, Florianópolis, SC. Revista Brasileira de Geociências, 37(3):565-578.

Leal M. \& Wagener A. 1993. Remobilization of anthropogenic copper deposited in sediments of a tropical estuary. Chemical Speciation Bioavailability, 24(1):31-39.

Mayer L.M., Macko S.A., Cammen L. 1988. Provenance, 
concentrations and nature of sedimentary organic nitrogen in the Gulf of Maine. Marine Chemistry, 25:291-304.

Mendonça Filho J.G. 1999. Aplicação de estudos de palinofácies e fácies Orgânica em rochas do Paleozóico da Bacia do Paraná, Sul do Brasil. Tese de Doutorado, Universidade Federal do Rio Grande do Sul, Santa Catarina, 2 vols. 338 p.

Mendonça Filho J.G. \& Menezes T.R. 2000. Palinofácies \& Fácies Orgânica. Apostila texto para o curso de Palinofácies e Fácies Orgânica, Universidade Federal do Rio de Janeiro, Rio de Janeiro, 160 p.

Mendonça Filho J.G., Menezes T.R., Oliveira A., Iemma M.B. 2003. Caracterização da contaminação por petróleo e seus derivados na Baía de Guanabara: aplicação de técnicas organogeoquímicas e organopetrográficas. Anuários do Instituto de Geociências da UFRJ, 26:69-78.

Mendonça Filho J.G., Carvalho M.A., Menezes T.R. 2002. In: Dutra T.L. (ed.) Palinofácies. Técnicas e Procedimentos para o Trabalho com Fósseis e Formas Modernas Comparativas. Unisinos, 1:20-24.

Mendonça Filho J.G., Menezes T.R., Mendonça J.O., Oliveira A.D., Carvalho M.A., Sant'Anna A.J. et al. 2009. Palinofácies. In: Carvalho I.S. (ed.). Palinologia, 3. (no prelo).

MenezesT.R.2002.Aplicaçãodeparâmetrospalinofaciológicos e organogeoquímicos na reconstrução paleoambiental do talude continental brasileiro recente na Bacia de Campos, $R J$. Dissertação de Mestrado, Universidade Federal do Rio de Janeiro, Rio de Janeiro, 174 p.

Meyer Reil L.A. 1994. Microbial life in sedimentary biofilms. The challenge to microbial ecologists. Marine Ecology Progress Series, 112:303-311.

Meyer Reil L.A. \& Köster M. 2000. Eutrophication of Marine Waters: Effects on Benthic Microbial Communities. Marine Pollution Bulletin, 41(1-6):255-263.

Müller J. 1959. Palynology of Recent Orinoco Delta and shelf sediments: reports of the Orinoco Shelf expedition, Micropaleontology, 5:1-2.

Premuzic E.T., Benkovitz C.M., Gaffney J.S., Walsh J.J. 1982. The nature and distribution of organic matter in the surface sediments of world oceans and seas. Organic Geochemistry, 4:63-77.

Quaresma V.S., Dias G.T.M., Baptista Neto J.A. 2000. Caracterização da ocorrência de padrões de sonar de varredura lateral e sísmica de alta freqüência $(3,5$ e 7,0 kHz) na porção sul da Baía de Guanabara. Brazilian Journal of Geophysics, 18(2):201-213.

Rebello A., Haekel W., Moreira I., Santelli R. \& Schroeder F. 1986. The fate of heavy metals in an estuarine tropical system. Marine Chemistry, 18:215-225.

Rebello A.L., Herms F.W., Wagener K. 1990. The cycling of iodine and iodate in a tropical estuarine system. Marine Chemistry, 29:77-93.

Santos E.S., Carreira R.S., Knoppers B.A. 2008. Sedimentary sterols as indicators of environmental conditions in southeastern Guanabara Bay, Brazil Brazilian Journal of Oceanography, 56(2):97-113.

Silva F.S., Pereira D.C., Nuñez L.S., Krepsky N., Fontana
L.F., Baptista Neto J.A. et al. 2008. Bacteriological study of the superficial sediments of Guanabara Bay, RJ, Brazil. Brazilian Journal of Oceanography, 56:13-22.

Siqueira G.W., Braga E.S., Mahíques M.M., Aprile F.M. 2006. Determinação da material orgânica e razões $\mathrm{C} / \mathrm{N}$ e $\mathrm{C} / \mathrm{S}$ em sedimentos de fundo do estuário de Santos- SP/Brasil. Arquivos de Ciências do Mar, Fortaleza, 39:18-27.

Stanley E.A. 1965. Abundance of pollen and spores in marine sediments off the eastern coast of the United States. Southeastern Geologist, 7:25-33.

Stubberfield L.C.F. \& Shaw P.J.A. 1990. A comparison of tetrazolium reduction and FDA hidrolysis with other measures of microbial activity. Journal of Microbiological Methods, 12:151-162.

Tyson R.V. 1995. Sedimentary Organic Matter. Organic facies and palynofacies. Londres, Chapman \& Hall, 615 p.

Tyson R.V. 1993. Chapter 5: Palynofacies analysis. In: Jenkins D.G. (ed.). Applied Micropaleontology. Kluwer Academic Publishers, The Netherlands, Amsterdam, p. 153-191 p.

Tyson R.V. 1989. Late Jurassic palynofacies trends, Piper and Kimmmeridge Clay Formations, UK onshore and northern North Sea. The British Micropalaeontological Society, p. 135-172.

Tyson R.V. 1987. The genesis and palynofacies characteristics of marine petroleum source rocks. In: Brooks J. \& Fleet A.J. (eds.) Marine Petroleum Source Rocks. Geological Society Special Publication, 26:47-67.

Tyson R.V. 1984. Palynofacies investigations of Callovian (Middle Jurassic) sediments from DSDP Site 534, BlakeBahama Basin, Western Central Atlantic. Marine and Petroleum Geology, 1:3-13.

Vandenberg C. \& Rebello A.L. 1986. Organic-copper interactions in Guanabara Bay, Brazil - an electrochemical study of copper complexation by dissolved organic material in a tropical bay. Science of the Total Environment, 58(12):37-45.

Vilela C.G., Sanjinés A.E.S., Ghiselli R.O., Mendonça Filho J.G., Baptista Neto J.A., Barbosa C.F. 2003. Search for bioindicators of pollution in the Guanabra Bay: integrations of ecologic patterns. Anuário do Instituto de Geociências UFRJ, 26:25-35.

Wall D., Dale B., Lohmann G.P., Smith W.K. 1977. The environment and climatic distribution of dinoflagellate cysts in modern marine sediments from regions in the North and South Atlantic Oceans and adjacent seas. Marine Micropaleontology, 2:121-200.

Whitaker M.F., Giles M.R., Cannon S.J.C. 1992. Palynostratigraphical review of the Brent Group, Uk Sector, North Sea. In: Morton A.C., Haszeldine R.S., Giles M.R. \& Brown S. (eds.). Geology of the Brent Group, Geological Society of London Special Publication, 61:169-202.

Ziervogel K. \& Bohling B. 2003. Sedimentological parameters and erosion behaviour of submarine coastal sediments in the south-western Baltic Sea. Geo-Marine Letters, 23:43-52.

Manuscrito ID 14583

Recebido em: 16/06/2009 Aprovado em: 07/03/2012 